\title{
Urdimento
}

\section{RAINHAS, SUTIÃS QUEIMADOS E BRUXAS CONTEMPORÂNEAS - REFLEXÕES A PARTIR DA MONTAGEM VINEGAR TOM}

\author{
Maria Brígida de Miranda
}

\begin{abstract}
Resumo
Este artigo está inserido no contex to da primeira montagem de Vinegar Tom no Brasil, produzida em 2007 e 2008 pela Universidade do Estado de Santa Catarina, nas disciplinas Montagem Teatral I e II, e das comemorações na Inglaterra do aniversário da dramaturga Caryl Churchill. Nesse âmbito, o artigo busca dar visibilidade a três assuntos correlatos por meio de: a) um panorama do 'teatro feminista' e contextualização da produção de Churchill; b) uma análise da obra de Churchill, em particular do texto Vinegar Tom, apontando estratégias e estéticas dos teatros feministas, e c) uma discussão sobre a montagem que dirigi de Vinegar Tom, defendendo a necessidade de inserção do estudo do teatro feminista nos âmbitos acadêmico e artístico brasileiros.
\end{abstract}

Palavras-chave: teatro feminista, Vinegar Tom, montagem, Caryl Churchill.

\section{A rainha do teatro feminista}

Celebrada pelo jornal inglês The Guardian como a dramaturga que "nos últimos 35 anos, criou os momentos mais importantes do teatro Britânico contemporâneo", Caryl Churchill completou vigorosos e produtivos 70 anos, no dia 3 de setembro de 2008, com celebrações públicas e artigos especiais sobre

\begin{abstract}
During the English colebrations of the birthday of playwright Caryl Churchill, this article presents itself as a text celebrating the first staging of Vinegar Tom in Brazil, produced in 2007 and 2008 by the University of the State of Santa Catarina, in the subjects Theatre Production I and II. The article seeks to give visibility to three correlating topics: a) the text presents a panorama of "feminist theatre" and contextualizes the work of Caryl Churchill; b) it highlights elements of Churchill's output, in particular from the work Vinegar Tom, which bring together and exemplify strategies and aesthetics of feminist theatres; c) the article focuses on the Brazilian production of Vinegar Tom, looking to the necessity of bringing the study of feminist theatre into the Brazilian academic and artistic spheres.
\end{abstract}

Keywords: feminist theatre, Vinegar Tom, Caryl Churchill, theatre production.
${ }^{1}$ Professora do Departamento de Artes Cênicas do Centro de Artes da Universidade do Estado de Santa Catarina.

${ }^{2}$ Exceto a citação do texto de

Sueli Gomes Costa, todas as citações deste artigo são originalmente em inglês, com tradução da autora.

Ravenhill, Mark. "She Made us Raise Our Game". The Guardian. Disponível em http:// www.guardian.co.uk/ stage/2008/sep/03/ carylchurchill.theatre Acesso em 07/09/08. 


\section{Urdimento}

2"The queen of alternative and feminist theatre turns 70 today". Disponível em http://www. guardian.co.uk/ stage/gallery/ 2008/sep/02/ carylchurchill? picure $=337204484$

Acesso em 07/09/2008.
${ }^{4}$ Ver COSTA (set-dez/2004). a sua vasta produção teatral. Em um país que mantém monarcas, a chamada do jornal "a rainha do teatro feminista e alternativo completa 70 hoje" pareceu ser uma coroação simbólica da polêmica Ms. Churchill ${ }^{3}$. O teatro Royal Court, parceiro de Churchill há décadas na montagem de suas peças, comemorou o aniversário da escritora promovendo um ciclo de leituras dramáticas, o Caryl Churchill Readings, no qual dramaturgos e dramaturgas selecionaram da vasta obra de Churchill sua peça favorita. Dentre as dez peças apresentadas estava Vinegar Tom (1976), texto feminista-socialista escrito por Churchill em colaboração com o grupo de teatro Monstrous Regiment. Tais celebrações, podemos supor, marcaram pela 'festa' o ato de dar visibilidade na esfera pública -- com deferência -- às obras de teatro feminista e alternativo de Churchill.

\section{Teatro feminista, um termo singular?}

O termo 'teatro feminista' já indica o embricamento entre duas práticas específicas. $\mathrm{O}$ teatro feminista seria uma prática teatral informada pelos discursos e causas feministas. Contudo, essa definição simples, complicase à medida que se percebe as multiplicidades de práticas teatrais e de práticas feministas. Se são inúmeras as possibilidades de 'fazer teatro', o feminismo não é um movimento único e homogêneo, mas um fenômeno com diferentes ideologias e demandas ao longo da história, moldadas por contextos políticosociais específicos. Se a premissa do feminismo é de que existe ao longo da história, e em diferentes culturas, a subordinação da mulher ao homem, as lutas do movimento feminista desde o século XIX são divididas em 'ondas' -- categorizando assim diferentes momentos históricos, portanto diferentes feminismos. Além disso, proliferam tanto os discursos filosóficos e teóricos que investigam as causas da subordinação feminina quanto os inúmeros caminhos e ações propostas por diferentes correntes feministas para combater a subordinação das mulheres na sociedade patriarcal. Esta heterogeneidade aplica-se na escolha do plural 'Feminismos' no lugar de 'Feminismo't.

Similarmente, para abarcar várias práticas teatrais feministas, autoras inglesas e americanas buscaram um termo plural: teatros feministas. Sue-Ellen Case (1990), Peggy Phelan, Lynda Hart (1993) e Michelene Wandor (1986) são algumas das autoras que já na década de 1980 e início de 1990 abordaram o aparecimento de grupos de teatro feminista nos anos 1960 e 1970, nos Estados Unidos da América e Inglaterra. Elas indicam as práticas de teatro feminista resultando de um entrecruzamento entre o teatro experimental e a segunda onda movimento feminista nestes países. Wandor (1986) situa o surgimento dos teatros feministas na Inglaterra a partir de 1968 e explica que a noção de 'diferença de gênero' ainda não era discutida pelo teatro alternativo, nem mesmo pelo teatro político. Tanto as peças teatrais como as encenações mantinham uma perspectiva e uma abordagem masculina sobre problemas sociais, econômicos e 
políticos, tendo sido, afirma Wandor, a "Revolução Teatral pós-1968” (1986:32) que trouxe assuntos relacionados à mulher e à orientação sexual para a agenda do teatro alternativo. Lizbeth Goodman (1993) concorda com Wandor sobre esta data para o surgimento dos teatros feministas na Inglaterra, fazendo, contudo, uma ressalva ao situar esse fenômeno como pós-1968, Goodman o demarca como a "segunda onda" do teatros feministas. A autora ainda alerta para a existência de práticas teatrais feministas na Inglaterra já no início do século XX. De fato, pesquisas históricas pioneiras como a de Julie Hollegde (1981) descrevem como mulheres de teatro do final do século XIX trouxeram as causas da primeira onda do movimento feminista para a prática teatral e a autora apresenta vários momentos dessas práticas. Dentre os mais significativos estão a formação de organizações de mulheres de teatro como a Actresses Franchise League e os grupos de teatro de mulheres como Pioneer Players dirigido por Edy Craig, irmã de Gordon Craig. A pletora de textos deste "novo teatro de mulheres" abordou "tabus como sexo, divórcio, doenças venéreas, prostituição" além de inovações na forma e romper com o espaço do edifício teatral, como o lugar do teatro, sendo as peças apresentadas em "ruas, salões de igrejas, teatros do West End, pistas de patinação no gelo -- em qualquer lugar" (HOLLEDGE, 1981: página de rosto). Esta 'primeira onda' de teatro feminista teria sido abruptamente rompida pela I Guerra Mundial.

A 'segunda onda' dos teatros feministas ganhou intensidade tanto nos eventos específicos do teatro como do movimento feminista. Goodman aponta alguns dos eventos que podem ter contribuído para esse florescimento, como o Ato do Parlamento Britânico em 1968 que aboliu a censura ao teatro, e a Primeira Conferência Nacional Britânica para a Liberação das Mulheres em 1969. Goodman amplia o contexto de influências ao abordar os incidentes nos Estados Unidos da América, como as grandes manifestações públicas de movimentos de mulheres, de 1969 até 1971, contra os concursos de Miss Mundo e Miss América. Para ela, estas manifestações podem ser vistas como teatralizações do repúdio contra as representações da mulher enquanto objeto sexual (GOODMAN, 1993: 24).

Naprática artística, a desestabilização derepresentações masculinas sobre as mulheres foi alvo já na década de 1960, de inúmeras artistas tanto em trabalhos solo como os de Carolee Schneemann como em coletivos, como o Female Fluxus. Rebecca Schneider (1997) destaca como essas artistas buscaram desestabilizar as representações da mulher na arte, por meio da performance e de suas obras de arte. Neste contexto, várias artistas usaram estratégias de auto-representação, mostrando-se como 'artistas' e não apenas como 'musas' ou 'objetos de arte'. As obras de arte de Schneemann e do Female Fluxus criam perspectivas feministas sobre o significado da arte, do próprio corpo e de como elas, como artistas, usam os próprios corpos na elaboração de representações do corpo feminino como um 


\section{Urdimento}

${ }^{5}$ Ver MIRANDA (2003).

${ }^{6}$ Embora seja um termo utilizado na língua inglesa, acho importante destacar o sentido forte que Ihe deu Paulo Freire, ao realçar a tomada de consciência e de atitude daquele que decide sobre seus atos e por ele se responsabiliza. Sobre 0 uso do termo, ver LAVOURA, Leira Paulo Freire. 0 educador brasileiro autor do termo empoderamento em seu sentido inovador. Disponível em http:// www.fatorbrasis. org/arquivos/Paulo Freire

Acesso em 22/10/2008.

${ }^{8}$ Ver DERRIDA; NASCIMENTO (2005). corpo ativo e produtor de arte. Especificamente na esfera teatral, se até 1968, na Inglaterra e EUA, a prática era ainda dominada por homens em cargos de poder (cargos de criação e decisão: autores, diretores, cenógrafos, produtores) e os produtos como o texto e a encenação, resultados desse universo masculino, a partir daquele momento as mulheres de teatro buscavam espaços próprios para exercerem tais funções. O direito a 'ter voz' nos processos de criação foi uma das principais motivações para que várias artistas deixassem seus grupos de teatro e se reunissem em grupos de teatro exclusivamente de mulheres. Vários desses grupos de teatro de mulheres nas décadas de 1960 e 1970 podem ser vistos como "espaços ginocêntricos" ${ }^{5}$, espaços de proteção e empoderamento ${ }^{6}$, onde as mulheres envolvidas assumiram responsabilidades por processos de criação e produção teatral. Pode-se afirmar que uma das principais características de grupos de teatro feministas é as mulheres participantes assumirem tarefas de criação e produção, abrindo-se espaço para a construção de representações de mulheres, de papéis e relações sociais a partir de olhares e vozes femininas. Os resultados vão desde os textos escritos por mulheres, passando por mulheres como foco da peça, até o direcionamento do discurso para outras mulheres.

Pode-se dizer que em várias das práticas de teatros feministas a produção de textos levou a transformação das próprias formas de produção e a questionamentos sobre hierarquias e relações de poder. Seguindo a tendência do teatro alternativo, funções como a do dramaturgo foram reformuladas ou diluídas em processos de criação coletiva. Tornou-se comum, por exemplo, a produção de tex tos a partir de improvisações e de temas ou experiências pessoais. A escrita de Vinegar Tom pode ser tomada como exemplo de uma prática comum ao teatro feminista destas décadas: o processo colaborativo. Embora o processo colaborativo e a criação coletiva não sejam uma exclusividade dos teatros feministas, estes espaços ampliaram as possibilidades de trabalho coletivo e colaborativo. Autoras com Alison Oddey (1998) e Elaine Aston (1999), além de defendem esse argumento, mapearam várias das estratégias para a criação de textos e espetáculos próprios, desenvolvidas em grupos de teatro feministas.

Muitos dos textos e espetáculos feministas produzidos nas décadas de 1960-70 revelam estruturas que desconstroem narrativas tradicionais (seguindo a vertente do pós-modernismo e do vocabulário de Derridá ${ }^{8}$ ) e quebram os limites entre teatro 'de texto' e o teatro físico, o teatro visual e o circo. Peta Tait, ao analisar as práticas teatrais feitas por mulheres na Austrália, observa que estas práticas "ampliam o espectro das formas teatrais existentes" (TAIT, 1994: 2). Como afirma Tait, a prática teatral feminista significa uma "construção de diferentes realidades teatrais"(idem). Portanto, pode-se concluir que, mesmo optando por numa perspectiva mais conservadora, a relevância de se estudar 'teatros feministas' nas universidades é a de que essas práticas 
significaram uma transformação da prática teatral, tanto no conteúdo e estética da peças teatrais e espetáculos quanto nas estratégias de criação e trabalho.

\section{Vinegar Tom - contexto e texto}

Qualquer texto de um grupo de teatro feminista reflete um teatro político com conteúdo relacionado às experiências e problemáticas de mulheres em contextos culturais particulares. A partir da década de 1960, estas problemáticas relacionam-se principalmente as demandas da 'segunda onda' do movimento feminista. Este é o ponto crucial que Goodman usa para contextualizar o debate anterior sobre os usos dos termos 'teatro de mulheres' e 'teatro feminista'. Enquanto o 'teatro de mulheres' é visto como um termo geral o 'teatro feminista' significa um comprometimento com o ativismo feminista. Goodman cita Susan Bassnett para explicitar essa relação entre 'teatro feminista' e ativismo':

$$
\text { […] O 'Teatro Feminista' logicamente baseia-se nas }
$$
preocupações estabelecidas pela organização do Movimento de Mulheres, sobre as sete demandas: igualdade de salários; igualdade de oportunidades de educação e de trabalho; creches gratuitas de 24 horas; contracepção e abortos gratuitos sob solicitação; independência legal e financeira; um fim a discriminação contra lésbicas e o direito a mulheres de definirem suas próprias sexualidades; luta contra a violência e a coerção sexual. Estas sete demandas, das quais quatro foram estabelecidas em 1970, e as restantes em 1975 e 1978 mostra, uma mudança em direção a um conceito mais radical de feminismo que afirma a homossexualidade feminina e percebe a violência partindo dos homens. (BASSNETT apud GOODMAN, 1993:30-1)

Neste âmbito, o texto Vinegar Tom pode ser visto como exemplo de uma produção de um grupo específico de mulheres, no contex to da Inglaterra dos anos 1970, que aborda diretamente várias das demandas do movimento feminista.

$\mathrm{O}$ ativismo feminista de Churchill e das integrantes do Monstrous Regiment pode ser percebido não apenas pela inserção da discussão sobre o abor to na peça Vinegar Tom, mas por vários outros temas apresentados na peça: a violência contra a mulher, tanto na esfera doméstica quanto pública; o estupro; a gravidez indesejada; a histeria; o casamento; o desejo sexual; o controle de natalidade, e a menopausa. $\mathrm{O}$ texto, estruturado de maneira brechtiana, em episódios (ao todo 21), aborda em cada quadro pelo menos um desses temas. As sete canções que entremeiam as cenas não se limitam a comentar a ação das personagens do século XVII, mas relacionam os problemas vividos por elas aos problemas vividos pelas mulheres na década de 1970 . 


\section{Urdimento}

${ }^{10}$ Uma primeira versão desta parte do trabalho foi apresentada na I Jornada Latino-Americana de Estudos Teatrais (Experimentalismos e Identidades), coordenada pelo Prof.Dr. AndréCarreira, atividade ligada ao Festival de Teatro Universitário de Blumenau, em julho de 2008. Agradeço aos participantes os comentários que me fizeram repensar determinadas questões apresentadas naquela ocasião.
Os assuntos que faziam parte problemática dos movimentos feministas da 'segunda onda' ganharam na escrita de Churchill/Monstrous Regiment uma historização. Há uma associação entre a falta de agência das mulheres na década de 1970 com uma subordinação histórica do corpo feminino ao olhar e controle da sociedade patriarcal em séculos anteriores. Churchill explica que quando foi convidada a escrever sobre a bruxaria ela tinha uma visão a partir da imagem das "fogueiras da inquisição, histeria e bacanais" que eram as representações mais freqüentes da 'caça as bruxas' em "filmes e ficção" (CHURCHILL apud REINELT 1990:156). No entanto, a partir da pesquisa que ela e o Monstrous Regiment realizaram nos arquivos de Essex sobre a 'caça as bruxas' elas perceberam como as acusações de bruxaria eram na verdade contra "ofensas corriqueiras e banais como a morte de uma vaca ou a manteiga que não vinha" (ibid.). Para Churchill, a bruxaria relacionavam-se à "pobreza, humilhação e preconceito e a auto-imagem das mulheres acusadas de bruxaria” (ibid.). Ou seja, eram principalmente a dependência econômica e a marginalidade que favoreciam a acusação de bruxaria imputada a certas mulheres, embora não fosse apenas isso.

Neste contexto, Vinegar Tom gira em torno da falta de possibilidade das mulheres (de várias idades, estados civis e poder aquisitivo) decidirem sobre os próprios destinos, o que em última instância significa tomar decisões sobre o corpo. O texto teatral explora a falta de poder sobre o próprio corpo a partir de uma contextualização social da problemática individual. Talvez, seja sintomático que Vinegar Tom tenha sido escolhida em 2008 para o Churchill Readings por Winsome Pinnock, dramaturgia com reconhecida produção de peças e textos sobre a situação mulher negra na Inglaterra. Pode-se especular se a peça continua 'atual' apenas por sua estrutura, ou se o conteúdo ainda seria pertinente no contexto inglês para as mulheres afro-descendentes e imigrantes, motivação da escolha de Pinnock para a leitura.

\section{Vinegar Tom: da queima de sutiãs às fogueiras da inquisição ${ }^{10}$}

Como coordenadora de um projeto de pesquisa acadêmico intitulado Poéticas do Feminino e Masculino: A prática teatral na perspectiva das teorias de gênero, propôs, desde sua implementação, em 2006, não apenas a investigação sobre as práticas de teatros feministas, mas também a abertura de um espaço escolar no qual discussões sobre representações do feminino e masculino no teatro pudessem ser iniciadas. A atividade envolvia o grupo de estudos Teatro e Gênero, aberto tanto para estudantes como para a comunidade em geral (mulheres e homens). Sintomático que nos três semestres de encontros o grupo fosse freqüentado unicamente por mulheres, em sua maioria alunas do curso de artes cênicas. Como sugestão, a primeira tarefa que propus ao grupo de estudos foi a de questionar as próprias 'representações' que cada participante trazia sobre os movimentos feministas, e a figura da 'feminista'.

Rainhas, sutiãs queimados e bruxas... Maria Brígida de Miranda.

Dezembro 2008 - № 11 


\section{Urdimento}

A principal representação revelada pelas participantes coincidia com a representação perpetuada em vários veículos de comunicação (incluindo inúmeros sites e blogs consultados na internet) relativas às manifestações do movimento feminista -- mulheres que queimaram sutiãs em praças públicas. Esta representação seria uma alusão a performance do Women's Liberation Group, em sua manifestação durante os desfiles de Miss America 1968, quando mulheres levaram vários objetos como vidros de laquê, sapatos de salto alto e sutiãs e os jogaram em uma lata de lixo. Se a performance teve o objetivo de simbolizar o repúdio dessas mulheres a uma única alternativa de 'ser mulher', ou seja de um universo feminino construído pela indústria e sociedade de consumo, a manchete do jornal do dia seguinte nomeava o ato como Bra-burning ${ }^{11}$ (queima do sutiã). Quarenta anos depois, celebrados também em setembro de 2008, uma das organizadoras do protesto, Carol Hanish ainda precisava explicar a 'distorção' do ato feita pelo jornal New York Post, repetida posteriormente por inúmeras mídias. Sintomático, talvez, a perpetuação dessa imagem - um fragmento de notícia que erotiza uma performance feita contra a objetificação do corpo feminino, restabelecendo, perversamente, a representação das mulheres como objetos sexuais. Ao recontar/recriar a performance, a mídia criou outra representação da mulher: a da fêmea indomável, feminista que num strip-tease arranca o objeto de fetiche para queimá-lo em praça pública.

Paralelamente à reavaliação desse tipo de representação, foram feitas, em nosso grupo, leituras introdutórias sobre a história do movimento feminista, e a partir de alguns conceitos trazidos pela teoria crítica feminista e estudos de gênero, iniciamos os debates sobre a desnaturalização da categoria 'mulher' e da noção de identidade fixa de gênero ${ }^{12}$. O estudo desse processo de 'desnaturalização' do 'feminino' e 'masculino' serviu como base para discussão do fazer artístico, especificamente da prática teatral. Como o teatro constrói representações de mulheres e homens a partir da repetição era uma das questões que Judith Butler discutira em Gender Trouble (1999), propondo a idéia de sexo como algo performativo. A partir daí nos perguntávamos: de que maneira autores teatrais constroem personagens femininas e masculinas? Há alguma diferença na escrita de autoras e autores teatrais? As autoras são necessariamente feministas, ou escrevem necessariamente de forma diferenciada dos homens? Para refletirmos sobre estas questões fizemos leituras de peças teatrais escritas por mulheres, dentre as quais Vinegar Tom (1976), a partir da tradução feita por uma das integrantes do grupo, a acadêmica Cláudia Mussi.

Após observar a receptividade no grupo de estudos, resolvi propor o texto Vinegar Tom para as disciplinas obrigatórias do curso de Artes Cênicas do Centro de Artes da UDESC, Montagem Teatral I e II, que ministraria, respectivamente, no segundo semestre de 2007 e no primeiro de 2008. O principal objetivo era introduzir na graduação em artes cênicas uma peça
${ }^{11}$ Greenfieldboyce, Nell. Pagent Protest Sparked Braburning Myth. Echos of 1968. NPR. Disponível em http://www.npr.org/ templates/story/ story. php? storyId $=94240375$ Acesso em 19/08/2008.

${ }^{12}$ Sabemos que este é um debate complexo que envolve problemas filosóficos ligados aos conceitos de natureza. Sobre o tema, veja, por exemplo, ASSMANN, Selvino José. Condição humana contra "natureza": diálogo entre Adriana Cavarero e Judith Butler. Revista Estudos Feministas, v. 7, p. 647-649, 2008. 


\section{Urdimento}

${ }^{13}$ Lembro que os nomes se referem às personagens históricas Heinrich Kramer e Jacob Sprenger, autores do manual de caça as bruxas Malleus Maleficarum, publicado em 1486. representativa de um tipo de teatro feminista, um texto onde o conteúdo e o formato enfatizam o engajamento com as causas do movimento feminista da 'segunda onda'. Considerando o número maior de mulheres cursando artes, um dos objetivos específicos foi o de oferecer melhores oportunidades de atuação, por meio de um texto com maior número de personagens femininas; e no qual as personagens femininas não são periféricas na trama. A escolha do texto Vinegar Tom me pareceu adequada, após uma estimativa do número de alunos e alunas previsto para a disciplina naquele semestre, a divisão de papéis por gênero seria possível necessitando pequenos ajustes, pois a peça tem 14 (quatorze) personagens e uma 'banda' musical. São 7 (sete) personagens femininos e 7 (sete) masculinos, sendo que 2 (dois) dos papéis masculinos, o dos inquisidores Kramer e Sprenger ${ }^{13}$, segundo sugestão da autora em nota de rodapé, devem ser feitos por mulheres.

Na apresentação da proposta para o colegiado do curso de artes cênicas e para o grupo de alunos/as a serem matriculados/as foi esclarecido que o trabalho sobre o texto de Churchill na graduação encontraria limitações como exercício da prática feminista. Não é novidade que quando atividades artísticas são realizadas em espaços complexamente hierarquizados e normatizados, como as universidades, há dilemas cruciais decorrentes da proposta de criticar e mesmo romper hierarquias. Neste sentido, uma típica prática feminista, que busca a verticalização das relações, estaria excluída do espaço da sala de aula, considerando todas as limitações que o/a professor/a e alunos/as estão submetidos quando neste contexto específico. Por outro lado, esta problemática pode ser de igual teor ao buscar-se encenar peças do teatro político ou alternativo, objetivando resgatar certas estratégias de construção e encenação no contexto de origem. O objetivo da proposta para a disciplina previa esta limitação e centrava-se na introdução de um texto de teatro feminista-socialista como 'objeto de estudo', neste caso um estudo por meio da leitura, discussão e da experiência da produção teatral, para alunos de graduação de uma universidade pública. Esta proposta encontrava precedentes em várias universidades americanas, inglesas e australianas onde o peça foi encenada e divulgada nos sites oficiais destas instituições.

Cientes da escolha de Vinegar Tom e de seu conteúdo e formato feminista, dezessete estudantes matricularam-se em minha turma, sabendo que, sob minha direção, executariam dois exercícios específicos da prática teatral: o trabalho de ator/atriz e o trabalho de realização do espetáculo. Em agosto de 2007 a turma, pela primeira vez, fez uma leitura dramática de Vinegar Tom. Durante esse mês repetimos esse procedimento, e essas leituras funcionaram tanto como momento dos/as alunos/as conhecerem o texto completo como de experimentarem a leitura de diferentes personagens - deixei claro que as leituras dramáticas contribuíam também para a definição do elenco. Durante e após a leitura, pedi 


\section{Urdimento}

que fizessem desenhos/escritas de imagens sugeridas pela leitura ${ }^{14}$. Essa foi uma estratégia para acessar o que cada um achava do texto, dos personagens, de como gostaria de ver o elenco formado. Tomei as decisões sobre elenco considerando não apenas a minha concepção do espetáculo, mas as sugestões que os/as alunos/ as deram por escrito, sobre o próprio papel e o dos/as colegas.

Mesmo que minhas escolhas refletissem as escolhas que os/as alunos/ as já haviam feito por escrito, havia ainda a manutenção do poder centrado no diretor, nesse caso uma mulher. A solução para amenizar a hierarquia nas relações entre diretora-atores/atrizes foi a de que as/os participantes fossem também responsáveis pela criação da encenação. Reunidas/os em equipes de trabalho, de acordo com suas escolhas, poderiam desenvolver a criação de figurinos, luz, cenário e objetos de cena; além da banda, que desfrutava um espaço privilegiado de criação. A equipe de preparação corporal foi conduzida no primeiro semestre pela mestranda Paula Rojas, na prática de Tai-Chi-Chuan, e os/as acadêmicos/as Elisza Schmidt, na condução de exercícios de Yoga, e Fabiano Lodi e Letícia Martins, na aplicação dos exercícios de View-Points ${ }^{15}$. Bárbara Biscaro atuou como voluntária na preparação vocal da banda, o que significava também um momento em que a liderança era passada da professora/ diretora para outros membros da equipe. Essa circulação de papéis de liderança é uma característica que pode ser vista como um exercício de empoderamento e agência. Outra solução para amenizar a hierarquia foi o de manter determinados horários ou mesmo dias, ao longo da disciplina, para a realização de discussões sobre o processo da montagem, nos quais decisões foram tomadas a partir de votações e acordos entre os/as acadêmicos/as e professora/diretora.

A importância da distribuição dos papéis, no primeiro no mês de aula, significou a definição de tarefas para cada aluno/a como ator/atriz. Com a personagem definida o/a aluno/a poderia concentrar-se na leitura de suas cenas e na construção da personagem a partir do entendimento do tex to e das tentativas de construção da partitura de ações físicas que a personagem precisaria realizar na cena. Enquanto eu trabalhava na construção de uma determinada cena com um grupo de atores, Rojas e Lia Motta (monitora), como assistentes de direção, trabalhavam com outros grupos de atores na leitura do texto e na identificação e construção de verbos de ação, de intenções que moveriam as personagens na cena. Assim, os personagens foram sendo construídos a partir de leituras do texto e durante o processo de construção da cena. No final do segundo mês o espetáculo já tinha 8 (oito) das 21 (vinte e uma) cenas esboçadas.

Ao final do semestre de Montagem Teatral I, o espetáculo completo já estava estruturado. Vinegar Tom foi apresentado com suas 21 cenas tipo 'episódios' interpretadas por 12 atores. As cenas eram intercaladas pelas
${ }^{14} 0$ suporte teórico para a interpretação foi também enriquecido com o Simpósio e Mostra de Vídeo Corpo Feminino, cuja primeira edição coordenado pela Profa. Dra. Silvana Macedo e por mim, em outubro de 2007, abordou o tema "Bruxaria e Histeria". 0 objetivo foi 0 de discutir as representações da imagem feminina por meio de textos, filmes e práticas sociais históricas e míticas. Foram abordadas questões relacionadas à representação de "corpos sexuados", especificamente a demarcação binária do "masculino" e do "feminino", com a finalidade de compreender certas figurações do feminino no teatro. Foram os seguintes os filmes exibidos e os debatedores convidados: Bruxa viva (L. Bastos, 1998) com Lena Bastos (cineasta) e eu; As Bruxas/Le Streghe (L.Visconti, M. Bolognini, P.P. Pasolini, F. Rossi, V. de Sica, 1967), com a Profa. Dra Fátima S. G Lisboa (Historiadora da Universidade Federal de Santa Catarina); Gritos de Mujer/ Kravgi gynaikon (J. Dassin, 1977) com a Profa. Dra. 


\section{Urdimento}

${ }^{14}$ (cont.) Maria Cecília de M.N. Coelho (filósofa da COGEAE/ PUCSP), bem como as palestras intituladas "Gênero, corpo feminino, história", da Profa. Dra Joana Maria Pedro (historiadora da Universidade Federal de Santa Catarina); "Sobre as Bruxas de Franklin Cascaes de Nossa Senhora do Desterro da Ilha de Santa Catarina", da Profa. Dra. Maria Isabel R. Orofino (UDESC) e "Histeria", da psicanalista Magdalena Souto da Silva.

${ }^{15}$ Bolsistas da pesquisa desenvolvida pela Profa. Dra. Sandra Meyer Nunes, no CEART/UDESC, sobre as técnicas de Viewpoints de Anne Bogart.

${ }^{16}$ Cláudia Mussi; Luana Garcia; Lívia Sudare e Fernanda Macedo. A banda foi nomeada pelas integrantes na época do espetáculo 'Aquela banda da montagem', após 0 fim da disciplina, elas adotaram Vinegar Tom como nome da banda.

${ }^{17}$ Renata Swoboda, que realizou também juntamente com o aluno Felipe Queriquelle as paisagens sonoras da peça. canções como sugerido no texto de Churchill. As 7 (sete) canções originais em inglês foram traduzidas e adaptadas totalizando 8 músicas (letras e melodias) criadas e tocadas ao vivo pela banda composta por quatro alunas ${ }^{16}$ da disciplina e uma aluna ${ }^{17}$ do curso de Música do CEART. O espetáculo tentou manter pelo figurino e objetos de cena o aspecto de peça histórica; ao passo que a banda 'comentava' e 'criticava' a situação vivida pelos personagens na cena, estabelecendo para a platéia um paralelo com assuntos contemporâneos, mantendo, assim, a proposta do texto de Churchill e da primeira encenação do Monstrous Regiment. O rompimento com a atuação realista era criado também pelo cenário, onde spots em backlight, projetavam em vários momentos do espetáculo luzes com sombras de galhos na parte superior dos painéis e a criação de sombras móveis e distorcidas a medida que os atores e as atrizes passavam por traz dos painéis. O objetivo destas sombras era provocar na platéia várias possibilidades de entendimento da cena; e ao mesmo tempo colocar o espectador na perspectiva daquelas personagens que viviam em um universo onde o 'mundano' e o 'real' conviviam com o fantasmagórico e assombrado. As sombras tinham a intenção de provocar a seguinte pergunta no espectador: essa pequena vila é um local sombrio e bruxólico, ou isso não passa de um grande engano coletivo?

A disposição das instrumentistas em relação as cenas no espaço teatral (Espaço 2, da UDESC) realçava nessas apresentações a posição privilegiada da banda (mulheres atuais) em relação a cena (história das mulheres). A banda tocava no mezanino atrás e superior ao espaço da cena. Deste espaço a banda poderia acompanhar a cena; e ser vista pela platéia, mas também ficava claro para a platéia que a banda também poderia observar os espectadores. Jill Dolan (1991) mostra como uma das preocupações das teorias feministas dizem respeito ao 'olhar' e a posição privilegiada do espectador. Nesse sentido o poder da banda de rock em 'olhar de volta' para a platéia pode sugerir que a relação de poder entre o espectador/a e o/a ator/atriz torna-se mais equilibrada. Este 'olhar de volta' para a platéia é explorado também nas cenas de duas 'mulheres velhas', as personagens Goody ${ }^{18}$, caçadora de bruxas, e Joan Noahs ${ }^{19}$, uma viúva que é acusada de bruxaria pela vizinhança. Assim, o espetáculo tentava criar momentos onde a teoria feminista encontrava espaços de aplicação.

O segundo semestre de trabalho, em Montagem II, constituiu o momento de circular o espetáculo por espaços fora do campus universitário. A possibilidade de apresentar em teatros de palco italiano e para públicos maiores com espectadores menos familiarizados às montagens do CEART implicou em algumas mudanças. A primeira dificuldade foi adaptar o cenário dos 9 painéis de tecido que eram suspensos por nylon; outro grande problema era a necessidade de re-posicionar banda de rock em relação as cenas. Se no Espaço 2 ela pôde ser estrategicamente colocada ao fundo e 


\section{Urdimento}

acima dos painéis, em outros teatros a banda teria de ocupar o mesmo nível da cena, sendo colocada na lateral esquerda de teatros como o teatro do Centro Integrado de Cultura (CIC), e também divida nas duas laterais do palco, como no Teatro Álvaro de Carvalho (TAC) e Teatro da Universidade Federal de Santa Catarina, todos em Florianópolis. Enquanto as adaptações do cenário geraram um momentum para o refinamento das cenas de sombras, as mudanças do local da banda geram dificuldades não apenas acústicas e de entrosamento entre os instrumentos, mas também dificultou as transições entre cenas e canções, alterando o tempo de deslocamento do foco de atenção da banda para os atores e atrizes.

Uma das principais mudanças nesta etapa foi o uso do tempo para refinamento do espetáculo que já havia sido apresentado completo no semestre anterior. Este refinamento consistiu em ensaios que melhoraram as transições entre as cenas. Além disso, houve uma melhora do ritmo e a conseqüente diminuição da duração do espetáculo (de 120 minutos nas primeiras apresentações de novembro de 2007 para 100 minutos na última apresentação, realizada no Teatro da UFSC em junho de 2008). Esses ensaios permitiram também que os atores e as atrizes como Kamila Bortolli (Margery), Fabiano Lodi (Jack), Fernanda Jacobo (Joan Noaks) e Maiara Barros (Beth) aprofundassem ainda mais suas caracterizações iniciais dessas personagens. Outros atores e atrizes passaram por transformações na maneira de perceber suas personagens, propondo mudanças no ritmo, postura corporal, motivações e ações das personagens, foram os casos de Tama Ribeiro (Helen), Daniel da Luz (Packer), Denise Krieger (Alice), Elisza Schmidt (Susan), e Felipe Queriquelli (Sprenger). Outros como Gilbas Piva, Aldo Godoy e Mariana Cândido construíram suas personagens e de diferentes maneiras tiveram de vivenciar o processo de, em um curto prazo, passar o trabalho que tinham desenvolvido para outros atores que os substituíram em apresentações especificas.

O momento de circulação do espetáculo Vinegar Tom gerou vários estímulos e oportunidades para todos os envolvidos no processo de repetirem a apresentação do trabalho, mas sempre com grandes desafios. Além da vivência de montar, apresentar e desmontar o espetáculo em diferentes espaços físicos, havia a necessidade de melhorar a projeção vocal e movimentação, ou alterar o ritmo da cena em função do tamanho do palco e configuração da platéia. A oportunidade de apresentar-se no Teatro como o do CIC, selecionado oficial do Festival Isnard Azevedo de 2008, constituiu um momento que todos/as atores/atrizes assumiram o desafio de sair do Espaço 2, com uma platéia de 70 espectadores para palco bem maior com uma platéia de 940 espectadores. Segundo o relato de todos os alunos envolvidos, na aula posterior a apresentação de abril de 2008, essa experiência foi a mais marcante.

Dezembro $2008-\mathrm{N}^{\circ} 11$

Rainhas, sutiãs queimados e bruxas... Maria Brígida de Miranda.
${ }^{17}$ (cont.) A orientação deste trabalho foi do Prof. Mst. Frederico Macedo, do Departamento de Música da UDESC.

${ }^{18}$ Interpretada por Mariana Cândido. Este papel foi interpretado pela Profa. Doutoranda Fátima Lima no espetáculo apresentado no Festival de Teatro Isnard Azevedo em 17 de abril de 2008 .

${ }^{19}$ Interpretada por Maria Fernanda Jacobo. 


\section{Urdimento}

${ }^{20}$ Disponível em http://brasil. notiemail.com/ noticia. asp?nt $=$ $12030387 \&$ cty $=2$ Acesso em 14/02/2008.
É preciso considerar que essas relações entre prática e teoria não são construídas necessariamente ao longo do processo de ensaio e aulas. Enquanto algumas reflexões são feitas em debates em sala de aula sobre o significado da cena, ou a relação entre cena e espaço teatral; outras reflexões acontecem a partir de leituras individuais ou de debates no grupo de estudos Teatro e Gênero. O que me parece ser uma realização importante com a produção de Vinegar Tom no curso de Artes Cênicas da UDESC é que reflexões sobre o espetáculo Vinegar Tom -- com sua estética e conteúdo de teatro feminista -podem continuar ocorrendo por bastante tempo, principalmente por aqueles/ as que vivenciaram o processo da Montagem Teatral I e II, como atores/ atrizes ou como professores/as e bolsistas de outros departamentos que colaboraram nesse processo.

Além do impacto dessas experiências para os participantes das disciplinas, há também as experiências dos/as espectadores/as que assistiram, alguns/as deles/delas mais de uma vez, o desenrolar desses episódios onde mulheres são acusadas de bruxaria, torturadas e levadas a forca por razões insólitas, e o medo do desconhecido, do marginalizado, faz dele ou dela uma visão assombrada de um futuro incerto. Se o projeto da disciplina não pretendeu discutir a recepção desta peça feminista-socialista, permaneceram as perguntas: Como os espectadores de Florianópolis, espaço historicamente povoado por casos bruxólicos, viram as 'não-bruxas' de Churchill? Teriam os espectadores associado em algum momento, a caça às bruxas da era moderna à caça aos terroristas da pós-modernidade? Será que os espectadores associaram as acusações da peça às acusações reais e atuais de bruxaria como as que recentemente condenaram Fawza Falih, na Arábia Saudita, à morte?

Fawza Falih foi detida pela Polícia religiosa ("Motawa) depois que várias pessoas a acusaram de praticar bruxaria contra si. Ela foi condenada à morte em 2006 por um tribunal da região de Quraiat, no norte do país. O comunicado indica que Falih não recebeu "garantias de um julgamento justo", já que não teve acesso a um advogado de defesa durante os interrogatórios nem durante o processo. Além disso, afirma que os juízes ignoraram as afirmações da acusada de que suas confissões durante o interrogatório foram arrancadas sob "pressão". Falih disse durante o processo que foi "torturada" e espancada durante os 35 dias nos quais ficou detida sob custódia da Polícia religiosa, onde foi obrigada a assinar um documento com confissões de que praticava bruxaria, sem saber seu conteúdo. A HRW lembra que na Arábia Saudita não há um Código Penal escrito, o que torna impossível encontrar uma definição para "bruxaria”o 
Considerando essa notícia, resta-nos concluir que mesmo sem as respostas do público de Florianópolis, peças dos teatros feministas precisarão, parece-me, continuar sendo lidas e encenadas, tanto por seu valor estético como histórico, e, também por seu escopo político, talvez ainda por muito tempo, infelizmente, tantas outras precisarão ser escritas.

\section{Referências bibliográficas}

ASTON, Elaine. Feminist Theatre Practice: A Handbook. London: Routledge, 1999.

BUTLER, Judith. Gender Trouble: Feminism and the Subversion of Identity. New York: Routledge, 1999.

CASE, Sue-Ellen. Performing Feminisms: Feminist Critical Theory and Theatre. Baltimore: The Johns Hopkins University Press, 1990.

CHURCHILL, Caryl. Vinegar Tom. Trad. Cláudia Mussi. (Texto não publicado, tradução realizada para a pesquisa Poéticas do Feminino e Masculino: A prática teatral na perspectiva das teorias de gênero).

COSTA, Sueli Gomes. "Movimentos Feministas, Feminismos". Revista Estudos Feministas, Número Especial, v. 12, Florianópolis, UFSC, setembro-dezembro/2004, 23-36.

DERRIDA, Jacques; NASCIMENTO, E. Pensar a desconstrução. São Paulo: Estação Liberdade, 2005.

DOLAN, Jill. The Feminist Spectator as Critic. 1988. Ann Arbor, Mich.: University of Michigan Press, 1991.

GOODMAN, Lizbeth. Contemporary Feminist Theatres: To Each Her Own. London: Routledge. 1993.

HART, Lynda; PHELAN, Peggy. Acting Out: Feminist Performances. Ann Arbor: The University of Michigan Press, 1993.

HOLLEDGE, Julie. Innocente Flowers: Women in the Edwardian Theatre. Virago: London, 1981.

MIRANDA, Maria Brígida de. 2003. 366f. Playful Training: Towards Capoeira in the Physical Training of Actors. Tese (Doctor of Philosophy). Theatre and Drama Department. Faculty of Humanitiesand Social Sciences. La Trobe University. Melbourne, Austrália.

ODDEY, Alison. "Devising (Women's) Theatre as Meeting the Needs of Changing Times." The Routledge Reader in Gender and Performance. Eds. Lizbeth Goodman and Jane de Gay. London: Routledge, 1998.

REINELT, Janelle. "Beyond Brecht: Britain's New Feminist Drama." Performing Feminisms: Feminist Critical Theory and Theatre. Ed. Sue-Ellen Case. Baltimore: The Johns Hopkins University Press, 1990. 


\section{Urdimento}

SCHNEIDER, Rebecca. The Explicit Body in Performance. London: Routledge, 1997.

TAIT, Peta. Converging Realities: Feminism in Australian Theatre. Sydney: Currency Press, 1994.

WANDOR, Michelene. Carry on, Understudies: Theatre and Sexual Politics. London: Routledge \& Kegan Paul, 1986.

\section{Sites}

ASSMANN, Severino J. "Condição humana contra "natureza": diálogo entre Adriana Cavarero e Judith Butler" Revista Estudos Feministas, v. 15, n. 3, Florianópolis, UFSC, setembro/dezembro/2007. Disponível em http: / / www.scielo.br/scielo.php? script=sci_arttext\&pid=So 104026X2007000300008\&lng=en\&nrm=iso Acesso em 08/09/2008

GREENFIELDBOYCE, Nell. Pagent Protest Sparked Braburning Myth. Echos of 1968. NPR. Disponível em http://www.npr.org/templates/story/ story.php?storyId=94240375 Acesso 19/08/2008.

RAVENHILL,Mark. "SheMadeus RaiseOurGame”. TheGuardian.Disponívelem http://www.guardian.co.uk/stage/2008/sep/03/carylchurchill.theatre. Acesso em 07/09/2008.

The queen of alternative and feminist theatre turns 70 today. Disponível em http://www.guardian.co.uk/stage/gallery/2008/sep/02/carylchurchill?\} picture $=337204484$ Acessado em 07/09/2008.

http://www.womenwriters.net/editorials/PriceEd1.htm> Acesso em 12/09/2008. 